\title{
Migration of Additives in Polyolefin Films Characterized by AFM
}

\author{
Shouren Ge,* Josh Chen,* Steve Werner,* Hoang Pham** and Nilesh Savargaonkar*** \\ * Analytical Science, The Dow Chemical Company, Freeport, Texas 77541 \\ ** Elastomers, The Dow Chemical Company, Freeport, Texas 77541 \\ *** Plastics TS\&D, The Dow Chemical Company, Freeport, Texas 77541
}

Migration of additives is a critical issue for polymers, especially polymeric food packaging materials [1]. In this study the migration of the additives to the polyolefin film surface was monitored by atomic force microscopy (AFM) using a pseudo-real-time experimental design in which the polyolefin films were preserved in dry ice immediately after formation and rinsed with methanol to remove the slip agent from the surface before AFM imaging. Movies of additive migration were generated from continuously scanned AFM topography and phase images.

IRGASURF® HL 560 (Irgasurf), one of additives investigated, has a chemical formula $\mathrm{CH}_{3} \mathrm{CH}_{2}\left(\mathrm{CH}_{2} \mathrm{CH}_{2}\right)_{\mathrm{a}}\left(\mathrm{OCH}_{2} \mathrm{CH}_{2}\right)_{\mathrm{b}}-\mathrm{OH}$. The molecules mainly consist of low molecular weight polymers with 9 repeat units for the A block and 2 to 4 repeat units for the B block. The longest molecule length is $3.6 \mathrm{~nm}$ for molecules with 3 repeat units in B block (Fig 1d). Fig. 1a shows the AFM image and section view of Irgasurf solution cast on mica. Irgasurf formed a well-defined layered structure on the mica surface with the layer thickness of about twice the length of the Irgasurf molecules. This implies that amphiphilic Irgasurf molecules tend to arrange themselves into bi-layer structures by positioning their hydrophobic chains towards the surroundings to reduce the interfacial energy. The bilayers of Irgasurf were also found on the PE surface during the migration progression (Fig 1b and 1c).

Fig. 2 shows a sequence of AFM phase images with the corresponding time at which the image was recorded. From the image sequence it is clear that the appearance and growth of the dark phase indicates the accumulation of Irgasurf on the polyethylene (PE) surface. The first significant indication of migration was observed at minute 68. During migration the phase image shows different tones of color, which indicates the different stages of migration. The light toned areas were unnoticeable in the AFM topography image suggesting the migrated molecules were random on the surface at an early stage of the migration process. Then, along with the continuous migration, molecules assembled into a bi-layer structure with a thickness of $\sim 6.5 \mathrm{~nm}$ (Fig 1b and 1c), which appears darker in the phase images. The time required for forming a complete layer on the surface was about $220 \mathrm{~min}$. This demonstrates how Irgasurf molecules migrate to the surface and arranges into an ordered structure and provides critical information on understanding additive migration process.

References

[1] T.R. Crompton, Additive Migration from Plastics into Foods, 2007. 

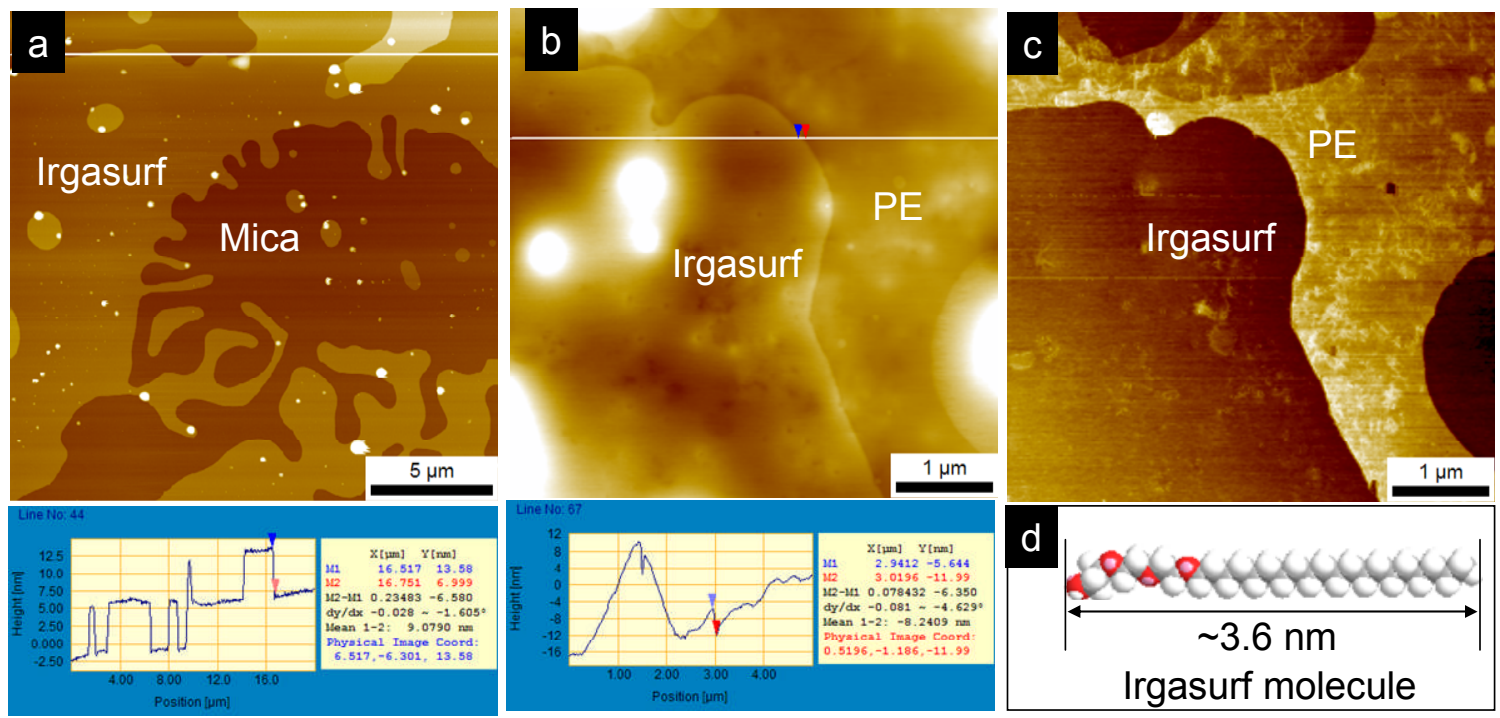

Fig. 1. Morphology of Irgasurf on different substrates. a) Topography of Irgasurf deposited on Mica; b) Topography of migrated Irgasurf on PE surface; c) Phase image acquired simultaneously with b; d) Molecular structure of Irgasurf with 3 repeat units in B block.
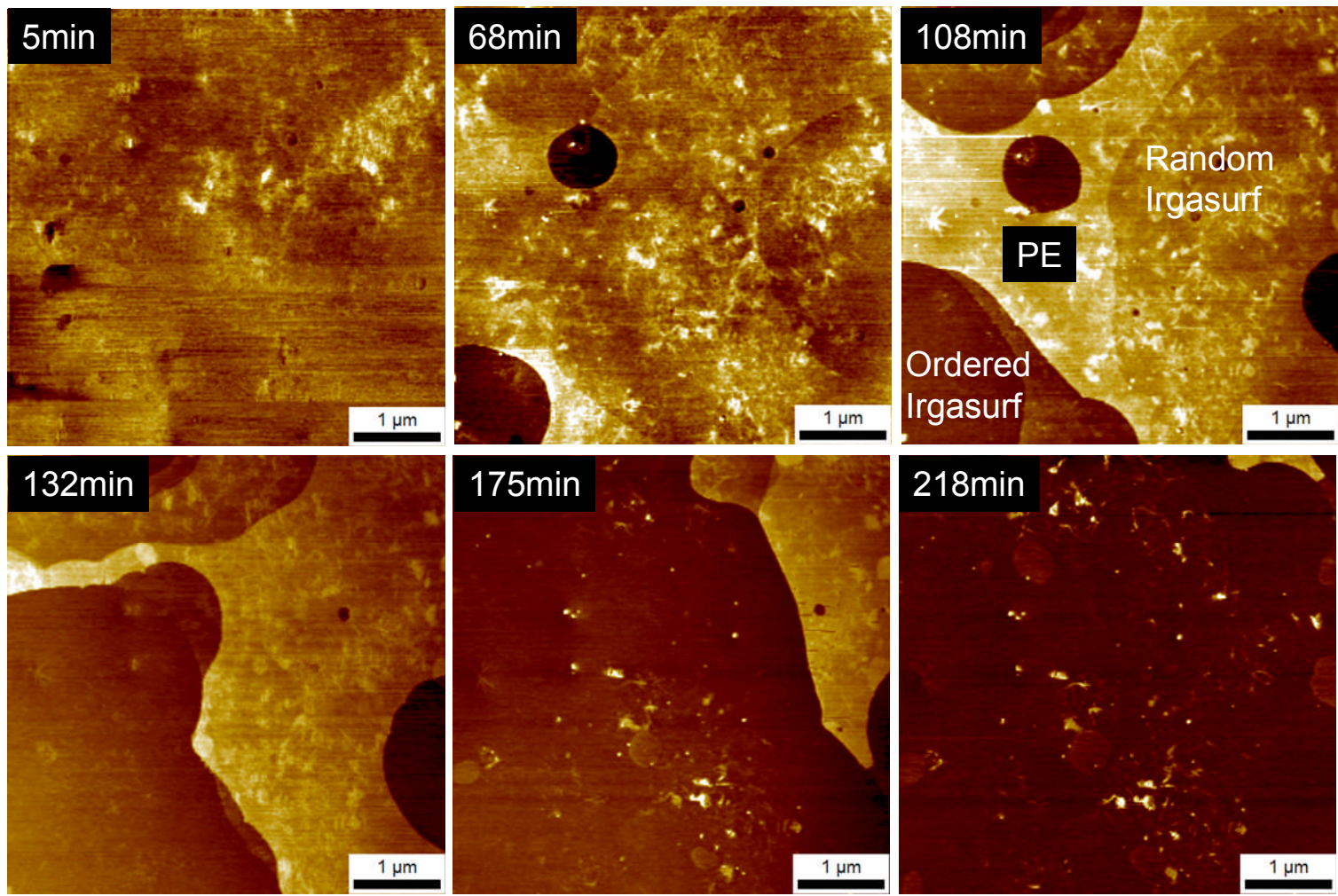

FIG. 2. AFM phase images with the corresponding time at which an image was recorded. 